\title{
PENERAPAN MODEL EVALUASI KIRKPATRICK EMPAT LEVEL DALAM MENGEVALUASI PROGRAM DIKLAT DI BALAI BESAR PELATIHAN PERTANIAN (BBPP) LEMBANG
}

\author{
Ramayana Ritonga, Asep Saepudin, Uyu Wahyudin \\ Program Studi Pendidikan Masyarakat \\ Sekolah Pascasarjana Universitas Pendidikan Indonesia \\ ramayana.ritonga@yahoo.com
}

\begin{abstract}
In Improving Human Resource Development (PSDM), the Lembang Center for Agricultural Training $(B B P P)$ is the right place to carry out technical training and functional training in agriculture. It has been proven that BBPP Lembang has printed a lot of skilled workers in the field of agriculture, this can be used as an indicator of the success of this training institution, not only that, the welfare of the farmers has also increased. BBPP Lembang is one of the places that can be used as a job that helps reduce the number of people who do not get jobs. To improve the ongoing training and on target BBPP Lembang always conducts evaluation activities that aim to see the success of the programs that have been held and follow up on the weaknesses that were obtained when the evaluation process took place both at the beginning of the program and at the end of the program. The application of the Kirkpatrick Four Level Evaluation Model is used as a frame of reference for evaluating programs, where evaluations at levels 1 and 2 will produce information for the organization about conducting training both in the middle and the end. Whereas levels 3 and 4 produce information that focuses on the impact of training for organizations and trainees.
\end{abstract}

\begin{abstract}
Abstrak: Dalam Meningkatkan Pengembangan Sumber Daya Manusia (PSDM), Balai Besar Pelatihan Pertanian (BBPP) Lembang menjadi tempat yang tepat sasaran untuk melaksanakan pelatihan teknis dan pelatihan fungsional di bidang pertanian. Sudah terbukti BBPP Lembang banyak sekali mencetak tenaga yang handal dibidang pertanian, hal ini bisa dijadikan sebagai indicator keberhasilan dari lembaga diklat ini, bukan hanya itu, kesejahteraan para petani pun sudah meningkat. BBPP Lembang menjadi salah satu wadah yang bisa dijadikan sebagai lapangan kerja yang membantu mengurangi jumlah warga yang tidak mendapatkan pekerjaan. Untuk meningkatkan pelatihan berkelanjutan dan tepat sasaran BBPP Lembang senantiasa melakukan kegiatan evaluasi yang bertujuan melihat keberhasilan program yang telah diselenggarakan dan menindaklajuti kelemahan-kelemahan yang didapat ketika proses evaluasi berlangsung baik di awal program dan maupun diakhir program. Penerapan Model Evaluasi Kirkpatrick Empat Level dugunakan sebagai kerangka acuan untuk mengevaluasi program, dimana evaluasi pada level 1 dan 2 akan mengasilkan informasi untuk organisasi tentang penyelenggaraan pelatihan baik diwal-tengan dan akhir. Sedangkan pada level 3 dan 4 menghasilkan informasi yang berfokus pada dampak pelatihan bagi organisasi dan peserta pelatihan.

Kata kunci: BBPP Lembang, PSDM, Model Evaluasi Kirkpatrick Empat Level
\end{abstract}

\section{PENDAHULUAN}

Balai Besar Pelatihan Pertanian (BBPP) Lembang merupakan salah satu Unit Pelaksana Teknis (UPT) Pusat Pelatihan Pertanian, Badan Penyuluhan dan Pengembangan Sumber Daya Manusia Pertanian (BPPSDMP), yang berdasarkan Peraturan Menteri Pertanian No. 101/Permentan/OT.140/10/2013 tanggal 9 Oktober 2013, mempunyai tugas yaitu malaksanakan pelatihan fungsional bagi aparatur, pelatihan teknis dan profesi, mengembangkan model dan teknik pelatihan fungsional dan teknis di bidang pertanian bagi aparatur dan non aparatur pertanian (www.bbpp-lembang.info). Berdasarkan Wexley dan Yukl dalam Prabu (2009), istilah pelatihan dan pengembangan sumber daya manusia mengacu pada upaya terencana yang dirancang dalam upaya memfasilitasi keterampilan, pengetahuan dan sikap yang relevan oleh anggota organisasi sedangkan pengembangan lebih focus pada peningkatan keterampilan pengambilan keputusan dan hubungan manusia manajemen tingkat menengah dan atas, sementara pelatihan 
melibatkan karyawan tingkat bawah dan presentasi materi pelajaran yang lebih factual dan sempit. Istilah tersebut selaras dengan Andrew E. Sikula (1981) bahwa pelatihan dan pengembangan adalah suatu proses pendidikan dengan waktu yang singkat yang terstruktur dan terorganisir untuk karyawan non manajerial dalam mendapatkan pengetahuan dan keterampilan dalam tujuan yang terbatas, sedangkan pengembangan adalah proses pendidikan yang dilakukan dalam waktu yang lebih lama degan prosesdur yang sistematis dan terorganisir yang karyawannya mempelajari pengetahuan konseptual dan teoritis untuk mecapai tujuan umum. Dalam setiap program pelatihan ada tiga tujuan bagi peserta pelatihan menurut Kirkpatrick, D., L. \& Kirkpatrick J., D. (2006) yaitu untuk memperoleh pengetahuan terkait pekerjaan mereka; untuk mempelajari keterampilan baru dan/ atau meningkatkan keterampilan mereka dan untuk mengubah sikap mereka. Adapun fungsi dari pelatihan dinyatakan oleh Noe, Hollenback, Gerhart, \& Wright dalam Ikramina \& Gustomo dalam Ramadhon (2014) adalah untuk mengembangkan pengetahuan dari pegawai tentang budaya perusahaan dan pesaingnya; untuk membantu pekerja yang mempunyai keterampilan dalam bekerja dengan menggunakan teknologi baru; untuk membantu pegawai dalam mamahami bagaimana bekerja secara efisien dan efektif dalam sebuah tim yang bertujuan untuk produk dan pelayanan yang berkualitas; untuk menjamin budaya perusahaan yang menekankan pada inovasi, kreativitas, dan pengetahuan; untuk menjamin keselamatan dengan memberikan ide-ide tentang bagaimana pekerja dapat berkontribusi kepada perusahaan dalam jam kerja yang aman; dan ketika para pegawai tersebut membutuhkan perubahan atau ketika suatu keterampilan baru dianggap wajib; serta untuk menyiapkan pegawai dalam menerima dan bekerja secara efektif antar sesama, khususnya dengan minoritas dan wanita.
Untuk mengidentifikasi keunggulan dalam program pelatihan perlu dilakukan evaluasi untuk memperbaiki kelemahan yang dimiliki program tersebut, (Rouse, D. 2011). Hal tersebut sesuai dengan tujuan evaluasi yang dikemukakan Wirawan (2011) yaitu untuk mengukur dan menilai apakah pelatihan mencapai tujuannya dengan mengidentifikasi kekuatan dan kelemahan suatu program. Menurut Vendung (2004) evaluasi adalah untuk melihat kebelakang, agar dapat menyetir kedepan untuk memonitor, mensistematikan, dan meningkatkan aktivitas pemerintah dan hasil-hasilnya, sehingga pejabat public dalam pekerjaannya dimasa yang akan datang dapat bertindak serta bertanggung jawab, kreatif, dan seefisien mungkin. Sedangkan kegiatan evaluasi menurut Kirkpatrick (2006) adalah untuk mengukur keefektifitasan program pelatihan, apakah sesuai dengan yang direncanakan, sehingga menjadi dasar bagi tim evaluator dalam membuat keputusan berdasarkan hasil evaluasi.

Definisi dan tujuan evaluasi tersebut secara implisit sesuai dengan definisi evaluasi dibidang pendidikan menurut UndangUndang Nomor 20 Tahun 2003 tentang Sistem Pendidikan Nasional, yaitu kegiatan pengendalian, penjaminan, dan penetapan mutu pendidikan terhadap berbagai komponen pendidikan pada setiap jalur, jenjang, dan jenis pendidikan sebagai bentuk pertanggungjawaban penyelenggaraan pendidikan. Ketika melakukan kegiatan evaluasi tersebut, hendaknya diperlukan suatu model evaluasi sebagai acuan yang mampu melakukan penilaian terhadap kualitas dan efektifitas pelaksanaan dari suatu program diklat. Model evaluasi empat level yang dikembangkan oleh Kirkpatrick merupakan kerangka konseptual untuk membantu menentukan data apa yang harus dijaring dalam evaluasi pengembangan sumber daya manusia. Lin \& Chuang (2011) mengatakan model evaluasi empat level Kirkpatrick merupakan model evaluasi yang level evaluasinya mencakup keseluruhan program 
untuk menilai apa yang kita butuhkan. Sedangkan Salvatore V. Falletta (1998)

model evaluasi Kirkpatrick yaitu (a) untuk membenarkan keberadaan fungsi pelatihan dengan menunjukkan bagaimana kontribusi untuk tujuan dan sasaran organisasi, (b) untuk memutuskan apakah akan melanjutkan program pelatihan, dan (c) meningkatkan pelatihan. Penyelenggaraan diklat pertanian yang dilaksanakan Balai Besar Pelatihan Pertanian (BBPP) ini diarahkan untuk dapat meningkatkan pengetahuan, sikap dan keterampilan sumberdaya manusia pertanian, sehingga pada gilirannya baik aparatur dan non aparatur mampu melaksanakan tugas fungsi/pekerjaan secara inovatif, kreatif, profesional dan berwawasan global. Melalui kegiatan evaluasi, diharapkan diperoleh informasi mengenai penerapan diklat, relevansi diklat, kebermanfaatan diklat serta implementasi petani di lapangan dan dapat pula dijadikan umpan balik bagi penyempurnaan program dan penyelenggaraan diklat yang akan datang.

\section{A. Tujuan}

Penerapkan model evaluasi empat level Kirkpatrick sebagai acuan dalam kegiatan evaluasi diklat Balai Basar Pelatihan Pertanian (BBPP) Lembang untuk menentukan apakah program diklat berjalan sesuai yang direncanakan dan mencapai tujuan yang ditetapkan.

\section{MODEL EVALUASI EMPAT LEVEL KIRKPATRICK}

\section{Kirkpatrick, (2006)}

dalam

Romadhon mengemukakan tiga alasan spesifik dalam melakukan evaluasi program pelatihan, yaitu: untuk menjustifikasi keberadaan anggaran pelatihan dengan memperlihatkan bagaimana program pelatihan tersebut berkontribusi pada tujuan dan sasaran organisasi; untuk menentukan apakah suatu program pelatihan dilanjutkan atau tidak; serta untuk memperoleh informasi mengenai bagaimana cara meningkatkan program pelatihan dimasa datang. Ia memberikan tiga alasan dasar untuk mengevaluasi pelatihan dengan

mengemukakan empat level evaluasi untuk menjawab tiga alasan tersebut, adalah: Level 1 Reaction (Reaksi), Level 2 Learning (Pembelajaran), Level 3 Behavior (Perilaku), dan Level 4 Results (Hasil/Dampak).

\section{A. Level 1 - Reaction (Reaksi)}

Reaksi didefenisikan sebagai kepuasan peserta mengenai program pelatihan (Kirkpatrick, D., L. \& Kirkpatrick J., D., 2007). Pentingnya reaksi peserta pelatihan merupakan salah satu penentu keberhasilan program. Untuk mengetahui tingkat kepuasan peserta Holton, F., E. (1996) mengatakan bahwa dalam proses menerima pembelajaran dibutuhkan motivasi untuk menimbulkan rasa ingin tahu. Pada dasarnya mengukur reaksi itu sangatlah penting karena dapat mengetahui apa yang dirasakan peserta mengenai penyelenggaraan program pelatihan dan memberikan saran dan masukkan, (Kirkpatrick, D., L. \& Kirkpatrick J., D., 2007). Langkahlangkah dalam melakukan evaluasi di level-1 adalah: 1. Membuat daftar item mengenai semua hal yang menyangkut penyelenggaraan program pelatihan seperti, kepuasan peserta terhadap materi, instruktur, konsumsi, materi, fasilitas, kepanitiaan dll. 2. Reaksi yang didapat di desain secara kuantifikasi dengan bentuk skala likert dan memberi ruang untuk komentar. 3. Ketika penilaian reaksi dilakukan jangan lupa meminta saran untuk perbaikan kepada peserta. 4. Menjaga kerahasiaan identitas peserta atau. 5. Lakukan evaluasi diakhir program untuk mendapatkan hasil yang maksimal.

\section{B. Level 2 - Learning (Pembelajaran)}

Evaluasi di level-2 ini merupakan pengukuran untuk level-3 yaitu perubahan perilaku yang artinya jika tidak ada perubahan perilaku artinya tidah adapembelajaran yang terjadi (Kirkpatrick, D., L. \& Kirkpatrick J., D., 2007). Pembelajaran di level-2 menurut 
(Kirkpatrick. 1979) adalah kompetensi peserta, baik dari segi pengetahuan, keterampilan, dan sikap sesuai dengan tujuan diadakannya pelatihan sebagai prinsip, fakta-fakta, dan teknik yang dimengerti dan diserap oleh peserta. Adapun tujuan pelaksanaan evaluasi belajar di level-2 menurut Kennedy, E., P., Chyung, Y., S., Winiecki, J., D., \& Brinkerhoff, O., R. (2013) adalah untuk mengetahui pemahaman peserta terhadap materi yang disampaikan. Dari definisi tersebut, pembelajaran berkaitan pengukuran prisip-prinsip pembelajaran, fakta-fakta, teknik-teknik, keterampilanketerampilan yang disajikan dalam program. Langkah-langkah dalam melaksanakan evaluasi di level-2, adalah: 1. Menggunakan grup kontrol sebagai pembanding. $\quad 2 . \quad$ Mengevaluasi pengetahuan, keterampilan dan sikap sebelum dan sesudah program. 3. Gunakan tes kinerja untuk mengukur peningkatan keterampilan. 4. Gunakan hasil evaluasi untuk melakukan tidakan yang sesuai

\section{Level 3 - Behavior (Perilaku)}

Ada tiga alasan mengapa evaluasi leve 3 perlu diperhatikan menurut Kirkpatrick, D., L. \& Kirkpatrick J., D. (2007) pertama, apakah perolehan pengetahuan dan keterampilan menghasilkan perilaku baru; kedua, satusatunya cara untuk mengetahui apakah kurangnya kesuksesan di level 4 disebabkan oleh pelatihan yang tidak efektif atau kurangnya tindak lanjut yang memadai; ketiga, tindak lanjut atau followup jangka panjang. Evaluasi level-3 dilakukan untuk membandingkan perilaku peserta sebelum dan sesudah mengikuti program, (Steensma, H., \& Groeneveld, K. 2010). Menurut Tan, K. \& Newman, E. (2013) evaluasi perilaku untuk melihat perubahan perilaku peserta ketika kembali bekerja dengan bekal kemapuan dan keterampilan yang didapatnya ketika pelatihan. Dari definisi tersebut dapat diartikan istilah perilaku dipakai dalam kaitan dengan pengukuran kinerja pekerjaan. Kirkpatrick, D., L. \& Kirkpatrick J., D. (2007) percaya bahwa tidak adak yang kurang dari empat cara yang bagu untuk mengevaluasi pada level 3 yaitu; 1. Melakukan survey dan kuesioner: menggunakan skala Likert dan pertanyaan terbuka yang bisa ditanyakan kepada siapapun yang mengamati perilaku peserta ditempat kerja. 2. Observasi dan daftar periksa: terdiri dari seseorang yang benar-benar mengamati karyawan di tempat kerja, dan biasanya merujuk ke tabel perilaku yang dinilai. 3. Tinjauan kerja: meninjau pekerjaan aktual yang telah selesai oleh peserta pelatihan di tempat kerja tanpa benar-benar mengamati mereka lakukan. 4. Wawancara dan kelompok fokus: terdiri dari pertanyaan terstruktur itu dapat dikelola untuk individu (wawancara) atau kelompok (kelompok fokus) untuk menanyakan sejauh mana perilaku baru sedang melamar pekerjaan. Mengevaluasi level-3 berarti mengukur perubahan perilaku yang disebabkan oleh program pelatihan. Mengevaluasi level-3 berarti mengukur perubahan perilaku yang disebabkan oleh program pelatihan. Dengan kata lain, apakah perubahan perilaku kerja terjadi ketika orang menghadiri pelatihan program; pertama, peserta pelatihan tidak bisa mengubah perilaku mereka sampai mereka memiliki kesempatan untuk melakukannya; kedua, tidak mungkin untuk memprediksi kapan perubahan perilaku akan terjadi; ketiga, peserta pelatihan dapat menerapkan pembelajaran pada pekerjaan. Langkah-langkah dalam melakukan evaluasi level-3 adalah: 1 . Evaluasi dilakukan ketika level 1 dan level 2 telah dilaksanakan. 2. Evaluasi dilakukan ketika pelaksanaan pelatihan benar-benar selesai dan para peserta telah kembali ke pekerjaannya masing-masing. 3. Mengevaluasi sebelum dan sesudah pelatihan jika memungkinkan 4. Metode evaluasi yang dilakukan dalah metode surveri dan wawancara kepada peserta pelatihan, atasan, teman sejawat dll. 5 . Evaluasi dilakukan kepada semua peserta 
pelatihan atau di sampel. 6. Mengulangi evaluasi pada waktu yang tepat 7 . Pertimbangkan biaya.

\section{Level 4 - Result (Hasil)}

Kirkpatrick, D., L. \& Kirkpatrick J., D. (2007) mengatakan evaluasi level ini evaluator menghubungkan hasil dari program dengan perbaikan organisasi. Rafiq, M. (2015) menyatakan bahwa evaluasi di level-4 apakah manfaat dari pelaihan berdampak bagi peserta pelatihan dan mencapai tujuan yang yang harapkan. Evaluasi hasil dalam Level 4 ini difokuskan pada hasil akhir (final result) yang terjadi karena peserta telah mengikuti suatu program. Evaluasi dilakukan terhadap perubahan kinerja institusi, misalnya membandingkan kualitas dan kuantitas hasil kerja serta waktu proses kerja, sebelum dan sesudah ada pelatihan. Dengan kata lain evaluasi Level ini adalah evaluasi terhadap impact program. Evaluasi hasil akhir ini dilakukan dengan membandingkan kelompok kontrol dengan kelompok peserta training, mengukur kinerja sebelum dan setelah mengikuti pelatihan. Tidak semua impact dari sebuah program dapat diukur dan kalaupun bisa diukur seringkali membutuhkan waktu yang cukup lama. Evaluasi level 4 memiliki kelebihan yaitu: 1) hasil yang didapatkan lebih komprehensif, karena mencakup hard skill dan soft skill yang dibutuhkan peserta dan lembaga. 2) sasaran dari pelaksanaan evaluasi tidak hanya hasil belajar semata tapi juga mencakup proses, output dan outcomes yang mereka dapatkan. 3) evaluasi ini mudah untuk dilaksanakan. Selain kelebihan tersebut model ini juga memiliki beberapa keterbatasan, antara lain: 1) kurang memperhatikan input; 2) untuk mengukur impact sulit dilakukan karena selain sulit tolak ukurnya juga sudah di luar jangkauan guru maupun sekolah. Langkah-langkah dalam melakukan evalausi di level- 4 adalah: 1 . Menggunakan control group. 2. Analisis tren atas kinerja. 3. Menggunakan metode peramalan atas kinerja. 4. Perkiraan peserta, atasa, jajaran atas pengeruh program pelatihan. 5. Menggunakan data historis. 6. Menghitung perkiraan adanya penyebab dari factor lain. 7. Berikan waktu untuk hasil yang ingin dicapai.

\section{EVALUASI PROGRAM DIKLAT DI BALAI BESAR PELATIHAN PERTANIAN (BBPP) LEMBANG}

Kegiatan evaluasi diklat di BBPP

Lembang dilakukan berdasarkan

Berdasarkan Peraturan Menteri Pertanian

Republik Indonesia Nomor:

101/Permentan/OT.140/10/2013 tanggal 9 Oktober 2013 tentang Organisasi dan Tata Kerja Balai Besar Pelatihan Pertanian Lembang, mempunyai tugas melaksanakan pelatihan fungsional bagi aparatur, pelatihan teknis dan profesi, mengembangkan model dan teknik pelatihan fungsional dan teknis di bidang pertanian bagi aparatur dan non aparatur pertanian. Evaluasi dilakukan setelah pelaksanaan diklat selesai yang merupakan kelanjutan dari evaluasi on going, pada saat diklat diselenggarakan yang dilakukan sebelumnya dan merupakan satu-kesatuan utuh yang tercakup dalam kerangka sistem Pengembangan Diklat Berbasis Kompetensi. Adanya kegiatan evaluasi, diharapkan diperoleh informasi mengenai penerapan diklat, relevansi diklat, kebermanfaatan diklat serta implementasi petani di lapangan dan dapat pula dijadikan umpan balik bagi penyempurnaan program dan penyelenggaraan diklat yang akan datang, (www.bbpp-lembang.info).

\section{A. Evaluasi Penyelenggaraan Diklat Di BBPP Lembang}

Model Evaluasi Empat Level Kirkpatrick menjadi acuan BBPP Lembang dalam mengevaluasi dimana level 1 bertujuan untuk melihat kepuasan peserta terhadap penyelenggaraan program pelatihan, level 2 untuk mengetahui apa saja yang dipelajari peserta dalam program pelatihan, level 3 untuk mengetahui apakah ada perubahan perilaku mereka 
berdasarkan apa yang mereka pelajari dan level 4 untuk mengetahui secara positif apakah perubahan perilaku mereka mempengaruhi organisasi. Evaluasi dilakukan ketika sebelum dan sesudah program pelatihan dilaksanakan. Evaluasi dilakukan dengan membuat kuesioner (level 1), Pre-Test Post-Tes (Level 2), wawancara, survey, FGD dll (level 3 dan 4).

\section{B. Evaluasi Pasca Diklat Di BBPP Lembang}

Evaluasi pasca diklat merupakan evaluasi yang difokuskan pada keberhasilan program baik untuk peserta, organisasi dan /atau kenaikan produksi akan perusahan. Evaluasi ini dilaksanakan pada akhir pelaksanaan program yang sama halnya dengan evaluasi sumatif yang mengukur kinerja akhir objek evaluasi dengan indicator; 1 . Menentukan sukses keseluruhan pelaksanaan program, 2. Menetukan cost dan benefit program, 3 . Mengkomunikasikan temuan evaluasi kepada para pemangku kepentingan, 4. Menentukan komponen yang paling efektif dalam program, 5. Menentukan apakah tujuan umum dan tujuan khusus program telah tercapai. Metode yang digunakan evaluasi pasca pelatihan adalah dengan mengaudit organisasi, analisis kinerja, analisis rekaman, observasi, survey, studi dokumentasi, dll. Peran dari evaluasi pasca diklat ini adalah untuk mengkonversi perubahan perilaku menjadi nilai-nilai yang terlihat dalam nilai manfaat dari program pelatihan. Jadi pada evaluasi pasca diklat ini berupaya mengambil keputusan apakah program berhasil dilaksanakan, harus dihentikan, dikembangkan dan di pidah ketempat lain.

\section{III.PENERAPAN MODEL EVALUASI EMPAT LEVEL KIRKPATRICK DALAM MENGEVALUASI PROGRAM DIKLAT DI BBPP LEMBANG}

Evaluasi yang digunakan dalam program pelatihan yang dilaksanakan BBPP lembang mengacu pada evaluasi formatif (yaitu metode yang menilai program saat proses pelatihan dilaksanakan) dan evaluasi sumatif (yaitu metode yang menilai program pasca pelatihan selesai dilaksanakan). BBPP Lembang menggunakan Model Evaluasi Kirkpatrick 4 Level yaitu evaluasi pada level 1 dan 2 akan mengasilkan informasi untuk organisasi tentang penyelenggaraan pelatihan baik diwal-tengan dan akhir. Sedangkan pada level 3 dan 4 menghasilkan informasi yang berfokus pada dampak pelatihan bagi organisasi dan peserta pelatihan.

\section{A. Level 1 - Reaction (Reaksi)}

Evaluasi terhadap reaksi bertujuan untuk mengetahui tingkat kepuasan peserta pelatihan terhadap penyelenggaraan pelatihan. Yang menjadi pertanyaan adalah: Mengapa tingkat kepuasan peserta mesti diukur? Apakah ada relevansinya terhadap pelatihan itu sendiri? Pertama, sesungguhnya evaluasi reaksi ini merupakan evaluasi terhadap proses pelatihan itu sendiri. Kualitas proses atau pelaksanaan suatu pelatihan dapat kita ukur melalui tingkat kepuasan pesertanya. Keduanya berbanding lurus. Semakin bagus pelaksanaan suatu pelatihan, akan semakin bagus pula respon kepuasan peserta terhadap penyelenggaraan suatu pelatihan; Kedua, kepuasan peserta terhadap penyelenggaraan atau proses suatu pelatihan akan berimplikasi langsung terhadap motivasi dan semangat belajar peserta dalam pelatihan. Peserta pelatihan akan belajar dengan lebih baik ketika dia merasa puas dengan suasana dan lingkungan tempat ia belajar. Mengetahui tingkat kepuasan peserta dapat dilakukan dengan mengukur beberapa komponen dalam pelatihan. Komponen tersebut meliputi: instruktur, kurikulum pelatihan, materi, metode belajar, suasana kelas, fasilitas, kepanitiaan konsumsi, dan lainlain yang berhubungan dengan penyelenggaraan program pelatihan. Mengukur reaksi ini dilakukan dengan menggunakan pernyataan yang berbentuk 
angket. Evaluasi terhadap reaksi ini sesungguhnya dimaksudkan untuk mendapatkan respon peserta terhadap kualitas penyelenggaraan pelatihan. Oleh karena itu waktu yang paling tepat untuk menyebarkan angket adalah sesaat setelah pelatihan berakhir atau beberapa saat sebelum pelatihan berakhir.

\section{B. Level 2 - Learning (Pembelajaran)}

Pada level ini untuk mengetes para peserta mengenai pengetahuan, keterampilan dan sikap sebagai akibat dari program pelatihan dan pengembangan. Para peserta diharapkan mampu memberikan jawaban seobjektif mungkin mengenai pembelajaran akan pengetahuan mereka ketika sebelum dan sesudah mari pembelajaran disampaikan. Evaluasi tahap kedua ini sesungguhnya evaluasi yang membandingkan terhadap hasil pelatihan sebelum dan sesudah pembelajaran yang mereka dapatkan ketika pelatihan. Semakin tinggi tingkat perbaikannya, dikatakan semakin berhasil pula suatu program pelatihan. Pengukuran yang dilakukan pada level ini lebih sulit dibandingkan dengan level 1. Oleh karenanya penggunaan alat ukur dan pemilihan waktu yang tepat akan dapat membantu kita mendapatkan hasil pengukuran yang sahih dan akurat. Alat ukur yang bisa kita gunakan adalah tes tertulis. Tes disini bisa menggunakan tes pilihan berganda ataupun tes isian yang isinya bersangkutan dengan materi inti yang akan disampaikan nantinya.

\section{Level 3 - Transfer (Behaviour)}

level tiga bertujuan untuk mengetahui sejauh mana pengetahuan dan keterampilan diterapkan dalam pekerjaan. Evaluasi level ini tidak bisa dilakukan sebelum evaluasi level pertama dan level kedua dilakukan. Bahkan ketika indeks kepuasan sangat bagus dan tujuan pembelajaran terpenuhi atau tercapai, transfer pengetahuan menjadi perilaku mungkin saja tidak terjadi. Pengukuran pada level ini dilakukan dengan menjawab pertanyaan: Apabila peserta telah selesai mengikuti diklat, perubahan perilaku apa yang terjadi? Perubahan perilaku dapat langsung terjadi begitu selesai diklat karena ada kesempatan untuk itu, tetapi bisa juga tidak terjadi karena tidak pernah ada kesempatan. Kirkpatrick mencatat ada 4 kondisi yang harus dipenuhi agar perubahan perilaku bisa terjadi; 1 . Peserta harus mempunyai keinginan dari dalam dirinya untuk berubah; 2. Peserta harus tahu apa yang harus dilakukan dan bagaimana melakukannya; 3. Peserta harus bekerja dalam iklim kerja yang mendukung; 4. Peserta harus diapresiasi perubahan yang dilakukannya. Syarat ketiga yaitu iklim yang mendukung, berkaitan dengan lingkungan kerja peserta diklat. Agar transfer pengetahuan dan keterampilan menjadi perilaku bisa terjadi, lingkungan juga harus mendukung terjadinya perubahan tersebut. Penerapan model evaluasi Kirkpatrick menunjukkan bahwa, pada tahap implementasi, lingkungan di mana peserta diklat bekerja sehari-hari lebih berpengaruh daripada pembelajaran itu sendiri.

$\begin{array}{rrr}\text { Beberapa } & \text { hambatan untuk } \\ \text { menerapkan } & \text { pengetahuan } & \text { dan }\end{array}$
keterampilan dalam pekerjaan antara lain: 1) Kurangnya kesempatan untuk mempraktikkan hasil pembelajaran; 2) Kurangnya kapasitas personal untuk menerapkan hasil pembelajaran; 3) Keyakinan bahwa usaha yang dilakukan tidak akan mengubah kinerja menjadi lebih baik; 4) Keyakinan bahwa kinerja yang diinginkan akan mempengaruhi nilainilai yang dianut oleh peserta; 5) Sejauh mana atasan secara aktif menghambat penggunaan pengetahuan dan keterampilan baru; 6) Dukungan atau resistensi dari rekan kerja ketika menggunakan pendekatan-pendekatan baru. Syarat keempat, yaitu apresiasi atau penghargaan terhadap perubahan, dapat bersifat instrinsik dan ekstrinsik. Penghargaan instrinsik adalah kepuasan psikologis yang diperoleh individu dari pekerjaannya. Ketika seseorang dihargai 
secara instinsik, dia akan lebih bersemangat dan bertekad untuk bekerja dengan lebih baik. Penghargaan ekstrinsik adalah imbalan ekonomis yang diterima dari orang lain, misalnya kenaikan gaji, pemberian bonus, dan imbalan lainnya. Banyak organisasi menghindari evaluasi level ketiga karena menghabiskan waktu, menambah biaya dalam proses diklat dan pengembangannya, dan seringkali kacau. Evaluasi level tiga dapat dilakukan dengan beragam cara, antara lain dengan melakukan survey terhadap atasan alumni diklat. Survey bisa dilakukan melalui email, telepon, surat, atau sarana lainnya. Atau bisa juga dilakukan dengan survey atau wawancara 360 derajat, yaitu kepada alumni diklat, atasan alumni diklat, rekan kerja, dan bawahan (jika ada), atau orang lain yang mengetahui perilaku alumni diklat, apakah ada perubahan perilaku setelah mengikuti diklat.

\section{Level 4 - Result (Hasil/Dampak)}

Evaluasi terhadap result bertujuan mengetahui dampak perubahan perilaku kerja peserta pelatihan terhadap tingkat produktivitas organisasi. Dalam skala yang lebih luas, hal ini menjadi tolak ukur mengenai kualitas lembaga terkait penyelenggaraan program pelatihan. Evaluasi result ini tidak hanya berhubungan dengan produktivitas, namun bisa lebih luas dari itu. Terbangunnya kerjasama yang makin solid dan kompak yang berimplikasi langsung terhadap motivasi dan suasana kerja dalam suatu organisasi. Jadi pada evaluasi level 4 menjadikan tujuan akhir dari ketiga evaluasi yang telah dilaksanakan, mengapa demikian?. Karena pada evaluasi level ini tidak hanya melihat dampak dari keberhasilan peserta akan pengetahuan dan keterampilan yang mereka dapat, perubahan sikap juga mempengaruhi pada lembaga/organisasi akan keuntungan yang diberikan kepada lembaga/organisasi. Apakah keuntungan tersebut muncul atau tidak muncul, dan diharapkan ketika di level ini berlanjut hendaknya ada follow up tim evaluator terhadap pemangku kepentingan. Agar produksi yang diharapkan memang benar-benar menguntungkan dari semua pihak, bukan satu pihak.

\section{KESIMPULAN}

Pelatihan merupakan sebuah proses mengajarkan pengetahuan dan keahlian tertentu, serta sikap terampil dan mampu melaksanakan tanggung jawabnya dengan semakin baik, sesuai dengan standar. Pelatihan merujuk pada pengembangan keterampilan bekerja (vocational) yang dapat digunakan dengan segera. Balai Besar Pelatihan Pertanian Lembang (BBPP) adalah lembaga yang melaksanakan pelatihan teknis dan pelatihan fungsional di bidang pertanian serta mengembangkan teknik pelatihan teknis di bidang holtikultura bagi aparatur pertanian serta melaksanakan pelatihan teknis dan kewirausahaan di bidang pertanian serta mengambangkan teknik pelatihan teknis dan kewirausahaan di bidang hortikultura bagi non aparatur pertanian dan melaksanakan proses pembelajaran (Mendidik, Mengajar, Melatih), mengembangkan dan menghasilkan media, paket pembelajaran, metodologi pelatihan teknis, fungsional dan kewirausahaan di bidang hortikultura dan pertanian lainnya bagi aparatur dan non aparatur.

Secara kenyataannya dilapangan (implementating) badan diklat BBPP ini sudah banyak sekali mencetak tenaga yang handal dibidang pertanian, hal ini bisa dijadikan sebagai indicator keberhasilan dari lembaga diklat ini, dan bukan hanya itu, kesejahteraan para petani pun sudah meningkat dan tentu saja lemabaga diklat ini pun bisa menjadi salah satu wadah yang bisa dijadikan sebagai lapangan kerja yang bisa membantu mengurangi jumlah warga yang tidak mendapatkan pekerjaan. Evaluasi dalam pelatihan dilakukan guna untuk mengambil keputusan atau memperbaiki proses pelaksanaan pelatihan menjadi lebih baik. Balai Besar Pelatihan 
Pertanian (BBPP) Lembang adalah lembaga pemerintahan dibidang pendidikan dan pelatihan pertanian yang setiap tahunnya ada program yang wajib dilaksanakan bagi purnawidyanya. Pelaksanaan evaluasi dilakukan untuk melihat kepuasan peserta pelatihan terhadap peroses pelaksanaan pelatihan dimulai dari tahap awal sampai dengan tahap akhir, kemudian evaluasi mengenai pengetahuan, sikap, dan kempuan yang didapat peserta pelatihan terhadap penyelenggaraan pelatihan. Evaluasi di BBPP Lembang yang mengacu pada Model Evaluasi Kirkpatrik 4 level menerapkan semua level yang ada dimana bukan hanya dievaluasi ketika proses pelatihan dilaksanakan saja, tetapi juga evaluasi pasca pelatihan untuk melihak hasil/dampak pelatihan baik itu untuk peserta, organisasi, dan juga benefit yang didapat.

\section{DAFTAR RUJUKAN}

Andrew, E. Sikula. 2011. Manajemen Sumber Daya Manusia. Bandung: Erlangga.

Badu, Q., S. (2013). The Implementation of Kirkpatrick's Evaluation Model in the Learning of Initial Value and Boundary Condition Problems. International Journal of Learning and Development, ISSN 2164-

4063, 2013, Vol.3, No.5.

Kirkpatrick, D. L. 1998. Evaluating Training Programs: The Four Levels. San Francisco: BerrettKoehler Publisher, Inc.

Vedung, Evert. 2004. Public Policy and Program Evaluation. New Brunswick, NJ: Transaction Publisher

Ramadhon, Syafril. 2014. Penerapan Model Empat Level Kirkpatrick Dalam Evaluasi Program Pendidikan Dan
Pelatihan Aparatur Di Pusdiklat Migas. Vol. 06 No. 1 Forum

Diklat. http://pusdiklatmigas.esdm.go.id diakses 4 Januari 2019, jam 08.00 WIB.

Holton, F., Elwood. (1996). The Flawed Four-Level Evaluation Model. Human Resource Development Quarterly; Spring 1996; 7,1 : ProQuest Health Management pg.5.

http://www.bbpplembang.info/index.php/p r ofil/sekilas-bbpp-lembang/sejarahbbpp lembang. Diakses 30

Desember 2018, jam 20.00 WIB.

http://www.bbpplembang.info/download/l ap oran_evpalat_2016_bbpplembang.

pd f Diakses 30 Desember 2018, jam 20.00 WIB.

Kennedy, E., P., Chyung, Y., S., Winiecki, J., D., \& Brinkerhoff, O., R. (2013). Training professional's usage and understanding of Kirkpatrick's level 3 and level 4 evaluations. International Journal of Training and Development 18:1 ISSN 1360-3736 doi: 10.1111/ijtd.12023.

Kirkpatrick, L., D. (1979). Techniques for Evaluating Training Programs. Training and Development Journal (june 1979): 178-192.

Kirkpatrick, D., L. \& Kirkpatrick J., D. (2006). Evaluating Training Program The Four Levels. San Fransisco : Berret-Kohler Publisher, Inc.

Kirkpatrick, D., L. \& Kirkpatrick J., D. (2007). Implementing The Four Levels: A Practical Guide for Effective Evaluation of Training Programs. San Fransisco : Berret- Kohler Publisher, Inc 
Peraturan Menteri Pertanian No.101 Tahun 2013

Prabu, Anwar Mangkunegara. 2009. Perencanaan dan Pengembangan Sumber Daya Manusia. Bandung: PT Refika Aditama.

Rafiq, M. (2015). Training Evaluation in an Organization Using Kirkpatrick Model: a Case Study of PIA. J

Entrepen Organiz Manag 4:151. Doi: $\quad 10.4172 / 2169$ 026x.1000151.

Rouse, Donald. (2011). Employing Kirkpatrick's Evaluation

Framework to Determine the Effectiveness of Health Information Management Courses and Program. Perspectives in Health Information Management, Spring 2011.

Steensma, Herman., \& Groeneveld, Karin. (2010). Evaluating a training using the "four-level model". Journal of Workplace Learning Vol. 22 No. 5, 2010. DOI:10.1108/13665621011053226

Tsan L., Y., Chuan, C., S., \& Chuang, H., T. (2011). The effect of organizational commitment on employee reactions to educational training: an evaluation using the Kirkpatrick fourlevel model. International Journal of Management Vol. 28 No.3 Part 2 September 2011.

Undang-Undang Nomor 20 Tahun 2003 Nasional tentang Sistem Pendidikan

Wirawan. 2012. Evaluasi: Teori, Model,

Standar, Aplikasi, dan Profesi: $\quad$ Contoh Aplikasi Evaluasi Program: Pengembangan Sumber Daya Manusia, Program Nasional Pemberdayaan Masyarakat (PNPM)
Mandiri Pedesaan, Kurikulum, Perpustakaan, dan Buku Teks. Jakarta: Rajawali Pers. 